\title{
INVESTIGANDO ESPAÇOS ESCOLARES DE LETRAMENTOS: A BIBLIOTECA E O LABORATÓRIO DE INFORMÁTICA
}

\author{
Lúcia Helena Schuchter* \\ Adriana Rocha Bruno **
}

\begin{abstract}
RESUMO
Este artigo configura-se a partir de uma pesquisa, que buscou compreender como são utilizados a Biblioteca Escolar e o Laboratório de Informática, enquanto ambientes de produção de leitura, escrita e conhecimento. Buscou-se fundamentação teóricometodológica na pesquisa qualitativa de abordagem histórico-cultural, respaldada por Lev S. Vygotsky e Mikhail Bakhtin. O campo de pesquisa constituiu-se de duas escolas situadas na cidade de Juiz de Fora, Minas Gerais. A investigação desenvolveu-se por meio de: (a) entrevistas semiestruturadas com dois bibliotecários, uma professora responsável pelo laboratório de informática, três professores e duas coordenadoras pedagógicas; (b) análise documental; (c) observação; e (d) questionário. A pesquisa aponta a possibilidade de trabalhos integrados na biblioteca escolar, no laboratório de informática e na sala de aula, e mostra a necessidade da formação para o uso das tecnologias a toda comunidade escolar.
\end{abstract}

Palavras-chave: Biblioteca escolar. Laboratório de informática. Letramentos. Formação de professores.

\section{ABSTRACT \\ INVESTIGATING LITERACY SPACES IN SCHOOL: THE SCHOOL LIBRARY AND THE COMPUTER LAB}

This article sets up from a research which aims to understand how the School Library and the Computer Lab are being used as reading, writing and knowledge production environments. It is based on qualitative research according to the historical and cultural approach and Lev S. Vygotsky and Mikhail Bakhtin studies. The field of research was two schools located in the city of Juiz de Fora in the state of Minas Gerais. The research developed by: (a) semi-structured interviews with two librarians, a teacher who was

\footnotetext{
* Doutoranda e Mestre em Educação pelo Programa de Pós-Graduação em Educação da Universidade Federal de Juiz de Fora (UFJF). Professora da Rede Municipal de Ensino de Juiz de Fora. Membro do Grupo de Pesquisa Aprendizagem em Rede (GRUPAR) desde 2009. Docente (Estágio docência) na disciplina Educação online: reflexões e práticas no Curso de Pedagogia (FACED/UFJF) a partir de 2013. Tutora da Coordenação de Inovação Acadêmica e Pedagógica no Ensino Superior (CIAPES/ PROGRAD/ UFJF) entre 2013-2014. Endereço para correspondência: Rua José Lourenço, 265, São Pedro, Juiz de Fora, MG. CEP: 36036-230. luciahschuchter@yahoo.com.br

** Mestre e doutora em Educação: Currículo (PUCSP). Professora da Faculdade de Educação/PPGE/PPGP da Universidade Federal de Juiz de Fora (UFJF-MG). Coordenadora de tutores a distância do Curso de Pedagogia (FACED-UFJF-UAB). Líder do Grupo de Pesquisa Aprendizagem em Rede (GRUPAR/UFJF). Coordenou a Coordenação de Inovação Acadêmica e Pedagógica no Ensino Superior (CIAPES /PROGRAD/UFJF) entre 2011 a 2014. Endereço para correspondência: Programa de Pós-Graduação em Educação - Universidade Federal de Juiz de Fora. Av. Presidente Costa e Silva, s/nº, Martelos, Juiz de Fora, MG. CEP: 36036-330. adriana.bruno@ufjf.edu.br
} 
responsible for the computer lab, three teachers and two pedagogical coordinators; (b) document analysis; (c) observation; and (d) questionnaire. The research indicates the possibility of integrated activities in the school library, in the computer lab and in the classroom, and it also shows the need for training the school community in the use of technology.

Keywords: School library. Computer lab. Literacies. Teacher Training.

\section{Introdução}

As temáticas que envolvem o uso das tecnologias da informação e da comunicação (TIC) nas diversas áreas do conhecimento no contexto escolar, aliadas à formação docente, têm sido frequentes nas pesquisas educacionais.

O movimento de informatização das escolas iniciou-se em alguns estados brasileiros em meados da década de 1980. Foi um período fértil, marcado pelo que foi batizado de Informática Educativa, em que pesquisadores e estudiosos vislumbravam na Linguagem Logo, de Seymour Papert (1985) e nos contatos e subsídios do Media Lab do Massachussets Institute of Technology (MIT), os caminhos para a incorporação tecnológica na educação. Nesse período, no Brasil, surgiram projetos e ações que buscavam implantar as tecnologias disponíveis nas escolas e formar professores para o uso pedagógico do computador. Passadas três décadas, poderíamos achar que a falta de formação docente para o uso das tecnologias estaria superada, já que hoje vivemos na cibercultura, temos a Web 2.0, Web 3.0, ambientes imersivos, redes sociais, mídias locativas. Infelizmente, o que as pesquisas realizadas recentemente sobre o uso das TIC na educação retratam não é um cenário de incorporação e apropriação tecnológica no lócus escolar.

Podemos encontrar subsídios para estas reflexões em trabalhos apresentados na ANPEd. ${ }^{1}$ Silva (2007) faz um resgate histórico das pesquisas, no Brasil, sobre a formação dos professores para o uso do computador na educação e afirma que se iniciam em 1985 por meio de projetos-piloto implantados

1 AANPEd-Associação Nacional de Pós-Graduação e Pesquisa em Educação - é uma sociedade civil, sem fins lucrativos, fundada em 1976. A finalidade da Associação é a busca do desenvolvimento e da consolidação do ensino de pós-graduação e da pesquisa na área da Educação no Brasil (ASSOCIAÇÃO NACIONAL DE PÓS-GRADUAÇÃO E PESQUISA EM EDUCAÇÃO, 2013). em diferentes universidades brasileiras (UFPE, UFRGS, UFMG, UFRJ e Unicamp). Destaca que com a criação do PROINFO $^{2}$ a formação de professores é sistematizada e inicia-se a distribuição de computadores às escolas públicas de todo o país. Lopes e Furkotter (2010, p. 15) afirmam que, ainda, "nas licenciaturas, os futuros professores aguardam por uma formação que, enfim, substitua temor por motivação e resistência ao desconhecido por determinação em superar o desafio que o ‘novo' representa”. Vizentim e Pesce (2010, p. 13) apontam que há no processo de formação vários fatores envolvidos: o desenho didático, os recursos, o envolvimento dos professores em formação e a proposta do formador, que deve "possibilitar aos futuros docentes uma experiência cultural, para além da experiência instrumental com as interfaces digitais".

As pesquisas continuam focalizando a relevância da prática pedagógica na promoção do letramento digital de alunos e professores, tomando a formação docente como núcleo fundamental desse processo.

No cenário escolar contemporâneo, encontramos os espaços tradicionais de fomento à leitura e à escrita - como as salas de aula e a biblioteca escolar - e os espaços emergentes - laboratórios de informática, sala de multimeios, rádio escola etc. Acreditamos que todos esses espaços escolares devem ser utilizados visando à tão almejada melhoria da qualidade da educação. A escola tem a função social, cultural e pedagógica de promover

2 "O Programa Nacional de Tecnologia Educacional (PROINFO) é um programa educacional criado pela Portaria ${ }^{\circ} 522 / \mathrm{MEC}$, de 9 de abril de 1997, para promover o uso pedagógico de Tecnologias de Informática e Comunicações (TIC) na rede pública de ensino fundamental e médio. O MEC compra, distribui e instala laboratórios de informática nas escolas públicas de educação básica. Em contrapartida, os governos locais (prefeituras e governos estaduais) devem providenciar a infraestrutura das escolas, indispensável para que elas recebam os computadores" (BRASIL, 2013). 
aprendizagem, de produzir conhecimento nos/com os aprendentes; logo, deve fornecer instrumental para que possam interagir com o conhecimento acumulado pelas várias disciplinas do currículo escolar através dos diversos dispositivos informacionais.

\section{Os letramentos: a leitura e a escrita em diferentes suportes textuais}

O Ministério da Educação do Brasil, através da "Política de Formação de Leitores", 3 apresenta a defesa da leitura como prática sociocultural, que deve estar inserida em um conjunto de ações sociais e culturais e não exclusivamente escolarizadas. Afirma que pensar políticas de leitura extrapola o âmbito da escola - como lócus e como função -, mas sem dúvida não pode prescindir dela. A leitura deve ser feita em variados suportes, a partir de múltiplas linguagens, relacionadas ao cinema, música, teatro, pintura, livro, computador. Esta prática é indispensável para o domínio da complexidade de gêneros textuais que circulam na sociedade contemporânea: leis, manuais de instrução, contas a pagar, jornais, livros, receitas culinárias, receitas médicas, filmes, e-mail etc.

Paulo Freire (1983) já sinalizava a necessária compreensão crítica do que se lê, implicando numa percepção das relações entre texto e contexto. Nesta perspectiva, em se tratando de leitura e da escrita, Soares (1998) nos traz um conceito que vai além da decodificação da palavra escrita. É um termo que veio do inglês literacy e foi traduzido para o português como letramento, que é "o estado ou condição de quem não apenas sabe ler e escrever, mas cultiva e exerce as práticas sociais que usam a escrita" (SOARES, 1998, p. 47).

Atravessamos uma época de profundas transformações tecnológicas que modificam as formas de ler e escrever. A educação reflete as características do tempo no qual está inserida. Surgem novos suportes de textos, mecanismos de produção, reprodução e difusão da escrita, o que para Soares (2002, p. 151) configura em um novo conceito:

\footnotetext{
3 "Um conjunto de documentos elaborados pelo Departamento de Políticas de Educação Infantil e Ensino Fundamental, da Secretaria de Educação Básica do MEC, com o objetivo de incentivar o debate acerca do papel da escola no desenvolvimento da competência leitora dos alunos." (BRASIL, 2006).
}

o letramento digital, isto é, "um certo estado ou condição que adquirem os que se apropriam da nova tecnologia digital".

Há, assim, "diferentes tipos e níveis de letramento" (SOARES, 1998, p. 49), que estão associados ao desenvolvimento da criticidade e da cidadania, pois implicam em ações de intervenção social e cultural dos sujeitos por meio das linguagens. Soares (2002) propõe o uso do plural letramentos para enfatizar a ideia de que diferentes tecnologias de escrita geram diferentes estados ou condições naqueles que fazem uso dessas tecnologias. Marcuschi (2005) também afirma que os gêneros textuais multiplicam-se a cada tecnologia que surge, e o termo letramento precisa ser expresso no plural. Vários são os letramentos, que estão intimamente ligados à materialidade histórica, social e cultural da escrita. Logo, acreditamos que ao dinamizar e ampliar o trabalho com a leitura-escrita em seus vários suportes, a escola oferece ao aluno a possibilidade de tornar-se letrado, acessar e produzir conhecimento. Os Parâmetros Curriculares Nacionais de Língua Portuguesa do Brasil (BRASIL, 1998) indicam, como um dos objetivos do ensino fundamental, que os alunos sejam capazes de "saber utilizar diferentes fontes de informação e recursos tecnológicos para adquirir e construir conhecimentos". Neste viés, a Biblioteca Escolar e o Laboratório de Informática são espaços que oferecem essas fontes e recursos - impressos e digitais - e ilustram todo o processo de mudanças tecnológicas, sociais, culturais e educacionais da atualidade.

A leitura e a escrita perpassam todas as disciplinas - com suas respectivas especificidades - e todos os professores são agentes de letramento, responsáveis por propiciar aos alunos o acesso e a produção do conhecimento, de forma colaborativa e crítica. Livros e computadores podem contribuir para que esse processo seja efetivado. Assim, com o intuito de suscitar na comunidade escolar uma reflexão sobre as possibilidades do uso desses espaços e sobre a leitura e a escrita em seus diferentes suportes (livro e computador), desenvolvemos uma pesquisa de mestrado que perseguiu pistas para a seguinte questão: no cenário tecnológico $e$ globalizado no qual estão inseridos, busca-se compreender como são utilizados, dentro da escola, a 
Biblioteca Escolar e o Laboratório de Informática, enquanto ambientes de produção de leitura, escrita e conhecimento.

\section{A pesquisa e seu percurso teórico-metodológico: achados e compartilhados}

Para desenvolver a pesquisa, buscamos fundamentação teórico-metodológica na pesquisa qualitativa, de abordagem histórico-cultural, respaldada por Vygotsky (1994, 2000) e Bakhtin (1988, 2003), encontrando suporte teórico nos estudos de Freitas (2003) e Pereira (2003).

Com o texto "Concepções teóricas da pesquisa em educação", Pereira (2003) objetiva contribuir e dialogar com aqueles que se iniciam na pesquisa, colocando que uma das questões centrais é saber que princípios, métodos e técnicas lhes possibilitam o estudo das problemáticas que se pretende estudar. A autora esclarece que a pesquisa em educação situa-se no âmbito do saber metódico, isto é, a ela cabem resultados racionais, compreensões, explicações dos fenômenos, intencionalidade e atitude reflexiva por parte do pesquisador. $\mathrm{O}$ caráter da intencionalidade vem das opções filosóficas, que definem as concepções de ciência, homem, sociedade, educação do pesquisador (que a partir delas indaga, elabora hipóteses, analisa os fenômenos). Assim, os resultados da pesquisa são históricos e podem ser revistos à luz de novos questionamentos e instrumentos de aprofundamento.

Ao analisar as pesquisas em educação do ponto de vista do materialismo histórico-dialético, esclarece que a relação sujeito-objeto se faz por um processo de implicação de um no outro, o que significa que os objetos se constituem na práxis do pesquisador. O saber científico é marcado pela história, pela existência social, que é contraditória. As pesquisas que se orientam à luz dessa perspectiva visam entender os fenômenos da educação na gênese e movimento dos próprios processos históricos, neles se desvelando e evidenciando constituições, permanências, mudanças.

Segundo Freitas (2003), nessa abordagem há uma nova postura do pesquisador em sua relação com o pesquisado: o pesquisador fala com o sujeito e não sobre o sujeito. A pesquisa se constrói social, histórica e contextualmente: é uma relação intersubjetiva possibilitada pela linguagem. Assim, compreendem-se os sujeitos através dos seus textos-palavras e seu contexto de trabalho, a partir dos fatos em seu processo histórico de acontecimento, compreendendo e descrevendo os fenômenos em estudo, estabelecendo relações intersubjetivas e participação ativa dos envolvidos na pesquisa (FREITAS, 2003). Convém ressaltar que a pesquisa, nesse enfoque, não é somente diagnóstica. É uma compreensão que Bakhtin (2003) denomina como ativa - que provoca uma ação/ reflexão - e responsiva - que provoca uma reação/ resposta. Este tipo de compreensão da realidade inevitavelmente leva a um processo reflexivo e interventivo, provocando transformações naqueles que participam da pesquisa.

A pesquisa com base na abordagem histórico-cultural reflete sobre o indivíduo em sua totalidade, abrangendo os aspectos pessoais e sociais que estão constantemente interligados. Este enfoque metodológico deve compreender o homem como um sujeito social, histórico e cultural, cujas ações sobre o mundo produzem a realidade.

Orientando-nos por essa perspectiva, desenvolvemos nosso trabalho investigativo. O campo de pesquisa constituiu-se de duas escolas públicas da cidade de Juiz de Fora, onde funcionam a Biblioteca Escolar (BE) e o Laboratório de Informática (LI). Foram utilizados os seguintes instrumentos de construção de dados: questionário, entrevistas semiestruturadas (feitas a partir de um esquema básico, permitem que o entrevistador faça as necessárias adaptações), observação e análise documental. Os sujeitos entrevistados - formados em diferentes áreas e com diferentes tempos de serviço - foram: dois professores responsáveis pela biblioteca escolar, um responsável pelo laboratório de informática, três regentes e duas coordenadoras pedagógicas.

Utilizamo-nos da observação, que segundo Lüdke e André (1986, p. 26) "possibilita um contato pessoal e estreito do pesquisador com o fenômeno pesquisado [...] E permite também que o observador chegue mais perto da 'perspectiva dos sujeitos', um importante alvo nas abordagens qualitativas". O conteúdo das observações envolveu uma parte descritiva - que compreende um registro detalhado 
do que ocorre "no campo", ou seja: descrição dos sujeitos; reconstrução de diálogos; descrição de locais; descrição de eventos especiais; descrição de atividades; comportamentos do observador. Envolveu também uma parte reflexiva das anotações - inclui as observações pessoais do pesquisador: suas especulações, sentimentos, problemas, ideias, impressões (BOGDAN; BIKLEN, 1994).

Recorremos, ainda, à análise documental, com o intuito de complementar informações. Guba e Lincoln (1981 apud LÜDKE; ANDRÉ, 1986, p. 39) resumem a vantagem do uso de documentos dizendo que "uma fonte tão repleta de informações sobre a natureza do contexto nunca deve ser ignorada, quaisquer que sejam os outros métodos de investigação escolhidos".

Os registros das observações, das entrevistas e de todo o percurso de pesquisa foram realizados por notas de campo.

Houve uma triangulação dos dados, buscando respostas à questão investigativa. As entrevistas nos permitiram evidenciar o perfil, a formação dos sujeitos e suas visões sobre os espaços investigados; os questionários e os Projetos Político-Pedagógicos (PPP) nos mostraram os contextos das escolas; as observações e os projetos de trabalho, ${ }^{4}$ as práticas pedagógicas dos professores no ambiente escolar.

Foi aplicado um questionário com a finalidade de fazer o mapeamento do uso da biblioteca escolar e do laboratório de informática por parte de todos os professores das duas escolas. Tivemos retorno de 29 dos 45 questionários, na Escola A. Na Escola B, 37 retornaram, de um total de 54 .

Em relação à pergunta "Você utiliza a biblioteca escolar?", na Escola A, 28\% dos professores dizem que sempre usam; em contrapartida, $28 \%$ afirmam que nunca usam, enquanto $44 \%$ a utilizam raramente. Já na Escola B, 22\% nunca utilizam a biblioteca escolar, 40\% utilizam raramente e 38\%, sempre.

Em relação ao Laboratório de Informática, na Escola A, apenas 17\% sempre o utilizam para atividades com alunos, enquanto $38 \%$ utilizam raramente e 45\%, nunca. Na Escola B, 54\% nunca o utilizam, $35 \%$, raramente e apenas $11 \%$ sempre utilizam.

4 Projetos de trabalhos: planejamentos de ações que serão realizadas pelos profissionais visando a um determinado objetivo. Apresenta-se o tema, justificativa, objetivos, cronograma de atividades, recursos que serão usados, critérios de avaliação.
Os dados de apenas um instrumento desta pesquisa já indicam um cenário pouco distinto do apresentado nas décadas de 1980 e 1990 sobre o uso do computador nas escolas.

A pesquisa em questão apresentou outras análises importantes: ainda há professores que não têm acesso às tecnologias. Nas Escolas A e B, 17\% e $9 \%$, respectivamente, não usam o computador. Outro fato que se destaca é que esses docentes dizem não saber como utilizá-lo.

Tais dados nos permitem afirmar que o que deveria estar superado - se considerarmos os quase trinta anos de início do processo de implantação do computador nas escolas - revela-se como algo a ser trabalhado: é preciso um redimensionamento da prática docente no que concerne ao uso do computador e (ainda!) do livro.

Desta forma, a questão que emerge nesse momento envolve a relação que os docentes estabelecem com livros e computadores, pois percebemos que cada professor tem uma visão singular e, muitas vezes, contrastante, que incide sobre suas práticas na escola:

A3: Não uso computador porque ainda não tive nenhuma vocação para conseguir gostar.

Pesquisadora: Você acha que precisa de vocação para usar o computador?

A3: É preciso ter jeito, paciência. E eu ainda não tive tempo para parar, me dedicar a isso.

A fala de A3 revela uma situação bastante comum nas escolas atuais: os professores nasceram numa época bastante diferenciada - em termos tecnológicos, culturais, sociais - do contexto histórico dos alunos que educam. Criam-se, em determinados momentos, verdadeiros "fossos", principalmente em relação ao uso das tecnologias. Mamede-Neves e Duarte (2008, p. 777) nos esclarecem:

Crianças e jovens 'nativos digitais' (PRENSKY, 2001), os que chegaram ao mundo após a popularização dos computadores pessoais e a criação da internet, compõem um segmento de usuários de TIC que não só faz uso corrente das mesmas como, também, antecipa o que está por vir, explora de forma criativa e diversificada tudo o que essas tecnologias têm a oferecer, ultrapassando, inclusive, os limites originalmente estabelecidos para o uso regular delas. 
Esta situação tão característica da época hodierna ${ }^{5}$ é bastante focada na fala do bibliotecário:

B1: Eu tenho uma neta de quatro anos, que aprendeu a mexer no computador antes de aprender a ler. No fim, ela tá lendo no computador.

Todavia, temos consciência de que muitos dos professores atuais são "estrangeiros digitais" (PRENSKY, 2001 apud SANTOS, 2008, p. 112), que não nasceram nesse contexto tecnologizado. Algumas enunciações dos sujeitos são altamente ilustradoras dessa situação nas escolas:

A2: A maioria dos professores ainda não é letrada em relação ao computador e principalmente à Internet. Muitos não gostam e não querem entender. Outros não se envolvem porque desconhecem. Outros têm medo ou vergonha e também não fazem por onde se interessar pela tecnologia.

B3: Porque, na verdade, é o seguinte: eu não tenho práticas de ensino voltadas para, eu não tenho formação para práticas de ensino mediadas pelo computador. Não tenho mesmo, tenho muita vontade, eu acho fundamental, mas eu não tive tempo hábil pra fazer isso ainda.

Diante dessas falas, as palavras de Gonçalves e Nunes (2006) ganham destaque, pois, em sua pesquisa, os autores perceberam que parcela significativa dos docentes investigados não recebera formação específica para lidar com as TIC. E lançam a pergunta: "Se os docentes não possuem formação adequada para trabalhar com tecnologias, como irão investir na formação dos discentes para as TIC?” (GONÇALVES; NUNES, 2006, p. 15).

Lévy (1999, p. 157) assinala que qualquer reflexão sobre formação na cibercultura deve levar em conta a mutação (qualitativa e quantitativa), a renovação e a velocidade do saber, alertando que: "pela primeira vez na história da humanidade, a maioria das competências adquiridas por uma pessoa no início de seu percurso profissional estarão obsoletas no fim de sua carreira".

\section{Considerações finais}

Para Pfromm Netto (2001, p. 195), “a aprendizagem humana é um processo multifacetado que

5 Hodierno (do latim hodiernus): que diz respeito ao tempo de hoje, ao tempo recente, atual. envolve múltiplas fontes de conhecimento, que interagem e exercem influência mútua". Logo, o foco da questão investigativa desta pesquisa apresentada não pode estar na relação livro versus computador, mas: (a) nas diferentes habilidades e possibilidades de leitura nestes suportes textuais, (b) na maneira como a escola pode e deve incorporar e promover esses diversos tipos de letramentos e; (c) nos benefícios - para a comunidade escolar e para toda sociedade - advindos destas práticas. Como nos ensina Larrosa (2006), é preciso ler no heterogêneo, multiplicar suas possibilidades de sentido, pois uma pedagogia não trata de buscar a homogeneidade dos saberes (que restringe a diferença), e sim a heterogeneidade do aprender (que produz e dá espaço à diferença). Acreditamos que, assim, garante-se a manutenção da alteridade, da possibilidade de crescimento, enriquecimento e constituição a partir do "outro", do "novo", do "diferente".

Essa opção, todavia, envolve os saberes e o comprometimento de todos os profissionais inseridos na escola para que se possa vencer um grande desafio da educação: preparar os indivíduos para se viver (bem) numa sociedade tecnologicamente instrumentalizada. Novas formas de transformar a prática pedagógica - entre uma nova postura do professor, uma nova cultura de ensino e de aprendizagem - devem ser concebidas. Do mesmo modo, vislumbramos a possibilidade de trabalhos integrados na biblioteca escolar, no laboratório de informática e na sala de aula. Como exemplo, podemos citar algumas atividades, inspiradas pelos contextos das próprias escolas pesquisadas: uma professora, que todos os anos trabalha com livros de Monteiro Lobato, pode propor uma pesquisa em que envolva o universo deste autor em sites, tais como:

a) lobato.globo.com;

b) www.projetomemoria.art.br/MonteiroLobato/index 2.html;

c) almanaque.folha.uol.com.br/monteirolobato.htm;

d) www.memoriaviva.com.br/mlobato/index2.htm.

Nestes sites, como é comum, há vários links, onde se podem obter informações sobre a vida, 
a obra, os personagens, as músicas do Sítio do Pica-Pau Amarelo, as receitas da Tia Nastácia etc. Será um exercício onde cada leitura irá conduzir a diferentes produções de sentidos, de acordo com o caminho escolhido pelo aluno-leitor.

As professoras que trabalham no Ensino Médio com livros de literatura voltados para o Vestibular podem fazer a leitura nos livros, porém podem, juntamente com os alunos, pesquisar na internet sobre os movimentos e estilos de literatura, biografias de autores, acessar exames vestibulares dos anos anteriores, visitar blogs literários, criar espaços de produção e de discussão online com os alunos, dentre outros.

É imensamente importante destacar que os trabalhos que envolvam a biblioteca escolar e o laboratório de informática devam estar previstos nas ações dos profissionais que neles atuam, dos professores regentes, dos coordenadores pedagógicos, e no Projeto Político-Pedagógico da escola.

Livros e computadores são mediadores do conhecimento, enquanto elementos da cultura que engendram diferentes processos de ler, de escrever, de se informar, de estabelecer relações sociais, de construir identidades. É tarefa da escola possibilitar o acesso a estes diferentes suportes, proporcionar aos alunos o convívio e o uso de diferentes gêneros textuais presentes na sociedade e desenvolver estratégias que habilitem o aluno à participação ativa nas práticas sociais letradas.

Vivemos num mundo de múltiplas linguagens (impressa, digital, televisiva, musical, imagética, cinematográfica etc.), e a escola, entretanto, nem sempre as integra ao seu fazer pedagógico. As escolas precisam de suportes (livros, televisão, jornais, DVD, computador etc.) para trabalhar com essas linguagens, e os espaços para que elas coexistam têm de ser ofertados e devem "conviver" cotidianamente com todas as atividades escolares e não estar segregados em um ambiente à parte, isolados, para eventuais "visitas". Para isso, não basta a existência de recursos "materiais", como livros e computadores; é preciso uma reflexão coletiva sobre o seu uso e disponibilizar seus acessos, aliados a uma formação docente condizente com os desafios da sociedade hodierna.

Sabemos da ineficiência das políticas de valorização dos professores, da precariedade das con- dições de trabalho, e é notória a necessidade de se criar reais condições para que os professores possam ter acesso às mais variadas tecnologias, aos bens culturais em geral, a cursos de formação para o desenvolvimento dos letramentos. Lembrando que, como afirma Rangel (2009), o letramento é um processo ininterrupto, no mundo que sempre exige novas aprendizagens. Acreditamos que se temos hoje professores que não estão incluídos e nem são letrados digitalmente, os programas de formação precisam estabelecer critérios, propostas e objetivos para ajudar a sanar esta defasagem. Há a necessidade de uma nova estrutura, um novo currículo, uma nova mentalidade, uma nova postura nos formadores de professores e novas pesquisas voltadas para metodologias de ensino - focalizando a leitura, os letramentos, o conhecimento tecnológico. Estes formadores têm de ser comprometidos ética e politicamente com a melhoria da qualidade dos cursos de formação, podendo gerar outra utilização do livro e do computador/internet dentro destes cursos, o que, logicamente, irá se refletir nas práticas docentes exercidas na escola.

Assim, considerando a diversidade encontrada entre os profissionais, a disponibilidade apresentada por eles, as demandas impostas pelo avanço das TIC e as condições espaço-temporais nos ambientes escolares, podemos pensar também na importância da formação continuada na modalidade a distância. Essa modalidade de ensino está prevista pelo MEC desde 1996, na Lei de Diretrizes e Bases, como uma das possibilidades de ampliação do ensino superior brasileiro, sendo considerada uma ferramenta eficaz, pois amplia o leque de opções de estudo.

A escola, a universidade e o poder público devem (co)responsabilizar-se pelo desenvolvimento, nos docentes e discentes, de habilidades de leitura e escrita em diferentes suportes, promovendo os plurais e necessários letramentos e garantindo o acesso desses leitores às novas mídias.

Enfim, é tempo de ressignificar a biblioteca escolar e o laboratório de informática - que precisam ser mais utilizados na escola -, para que se transmutem em espaços coletivos de leitura, escrita, pesquisa, interação, produção de conhecimento. É tempo de, imbuídos do espírito investigativo 
e reflexivo inerente a nós professores e pesquisadores, criar possibilidades de relações entre o possível-desejável, entre o real-ideal, entre o impresso-digital, entre a vida-educação, enquanto vamos nos constituindo como seres inconclusos e imperfeitos em eterna (trans)formação.

\section{REFERÊNCIAS}

ASSOCIAÇÃO NACIONAL DE PÓS-GRADUAÇÃO E PESQUISA EM EDUCAÇÃO (ANPEd). Apresentação. Disponível em: <http://www.anped.org.br/anped/sobre-a-anped/apresentacao>. Acesso em: 18 abr. 2013.

BAKHTIN, Mikhail. Gêneros do discurso In: Estética da criação verbal. São Paulo: Martins Fontes, 2003. p. 261-306.

Marxismo e filosofia da linguagem. 4. ed. São Paulo.: Hucitec, 1988.

BOGDAN, Roberto C.; BIKLEN, Sari K. Investigação qualitativa em educação, uma introdução à teoria e aos métodos. Porto, Portugal: Porto Editora, 1994.

BRASIL. Ministério da Educação. Parâmetros Curriculares Nacionais: língua portuguesa. Brasília: MEC/SEF, 1998. Disponível em: <http://portal.mec.gov.br/seb/arquivos/pdf/portugues.pdf>. Acesso em: mar. 2013.

Ministério da Educação. Programa Nacional de Tecnologia Educacional (PROINFO). Apresentação.

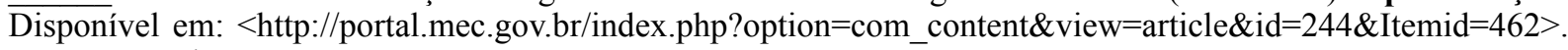
Acesso em: abr. 2013.

Ministério da Educação. Por uma política de formação de leitores. Brasília, 2006. Disponível em:

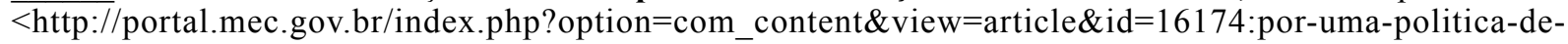
-leituras\&catid=195\&Itemid=86>. Acesso em: jul. 2013.

FREIRE, Paulo. A importância do ato de ler. São Paulo: Cortez, 1983.

FREITAS, Maria Teresa A. A perspectiva sócio-histórica: uma visão humana da construção do conhecimento. In: FREITAS, Maria Teresa; SOUZA, Solange Jobim; KRAMER, Sônia (Org.). Ciências humanas e pesquisa: leitura de Mikhail Bakhtin. São Paulo: Cortez, 2003. p. 26-38.

GONÇALVES, Marluce T.; NUNES, João B. Tecnologias de informação e comunicação: limites na formação e prática dos professores. In: REUNIÃO ANUAL DA ANPEd, 29., 2006, Caxambu. Anais... Caxambu: ANPEd, 2006. GT 16: Educação e Comunicação.

LARROSA, Jorge. Pedagogia Profana: danças, piruetas e mascaradas. 4. ed. Belo Horizonte: Autêntica, 2006.

LÉVY, Pierre. O que é cibercultura. São Paulo: Ed. 34, 1999.

LOPES, R. P.; FURKOTTER, M. Formação para o uso das tecnologias digitais de informação e comunicação nas licenciaturas presenciais das Universidades Estaduais Paulistas. In: REUNIÃO ANUAL DA ANPEd, 33., 2010, Caxambu. Anais... Caxambu: ANPEd, 2010. GT 08: Formação de Professores.

LÜDKE, Menga; ANDRÉ, Marli E. D. A. Pesquisa em educação: abordagens qualitativas. São Paulo: EPU, 1986.

MAMEDE-NEVES, M. Aparecida C.; DUARTE, Rosália. O contexto dos novos recursos tecnológicos de informação e comunicação e a escola. In: Educação \& Sociedade, Campinas, v. 29, n. 104, p. 769-789, out. 2008. Edição Especial. Disponível em: <http://www.scielo.br/pdf/es/v29n104/a0729104>. Acesso em: mar. 2013.

MARCUSCHI, Luiz A. Gêneros textuais: definição e funcionalidade. In: DIONÍSIO, Ângela P. (Org.). Gêneros textuais \& ensino. 4. ed. Rio de Janeiro: Lucerna, 2005. p. 19-36.

PAPERT, Seymour M. Logo: computadores e educação. São Paulo: Brasiliense, 1985.

PEREIRA, Maria de Fátima R. Concepções teóricas da pesquisa em educação. In: LOMBARDI, José C. (Org.). Globalização, pós-modernidade e educação: história, filosofia e temas transversais. Campinas, SP: Autores Associados, 2003. p. 129-143.

PFROMM NETTO, Samuel. Telas que ensinam: mídia e aprendizagem do cinema ao computador. São Paulo: Alínea, 2001. 
RANGEL, Flamínio de Oliveira. Mediação pedagógica em EAD: a falta de tempo como sintoma. 2009. $210 \mathrm{f}$. Tese (Doutorado em Educação) - Pontifícia Universidade Católica de São Paulo (PUC-SP), São Paulo, 2009.

SANTOS, Edméa O. A metodologia da Webquest interativa na educação online. In: FREIRE, Wendel (Org.). Tecnologia e educação: as mídias na prática docente. Rio de Janeiro: Wak, 2008. p. 107-128.

SILVA, Adriana R. A inserção do computador na prática pedagógica do professor: formação, concepções e práticas de professores-instrutores. In: REUNIÃO ANUAL DA ANPEd, 30., 2007, Caxambu. Anais... Caxambu: ANPEd, 2007. GT 08: Formação de Professores.

SOARES, Magda. Letramento: um tema em três gêneros. Belo Horizonte: Autêntica, 1998.

. Novas práticas de leitura e escrita: letramento na cibercultura. In: Educação \& Sociedade, Campinas, v. 23, n. 81, p. 143-160, dez. 2002. Disponível em: <http://www.scielo.br/pdf/es/v23n81/13935>. Acesso em: mar. 2013.

VYGOTSKY, Lev S. Problemas de método. In: A formação social da mente: o desenvolvimento de processos psicológicos superiores. SP: Martins Fontes, 1994. p. 67-85.

A construção do pensamento e da linguagem. São Paulo: Martins Fontes, 2000.

VIZENTIM, R.; PESCE, L. Os recursos de linguagem como contribuição à construção de sentidos entre formadores e professores universitários em formação no contexto digital. In: REUNIÃO ANUAL DA ANPEd, 33., 2010, Caxambu. Anais... Caxambu: ANPEd, 2010. 